\title{
Errors associated with the preparation of aseptic products in UK hospital pharmacies: lessons from the national aseptic error reporting scheme
}

\author{
Richard Bateman, ${ }^{1}$ Parastou Donyai ${ }^{2}$
}

- Additional appendices are published online only. To view these files please visit the journal online (http://qshc.bmj. com)

${ }^{1}$ East and South East England Specialist Pharmacy Services, Guy's Hospital, London, UK ${ }^{2}$ Reading School of Pharmacy, Whiteknights, Reading, UK

\section{Correspondence to}

Dr Parastou Donyai, Reading School of Pharmacy, University of Reading, PO Box 226, Whiteknights, Reading RG6 6AP, UK;

p.donyai@reading.ac.uk

Accepted 21 December 2009 Published Online First 27 April 2010

\begin{abstract}
Background Pharmacy aseptic units prepare and supply injectables to minimise risks. The UK National Aseptic Error Reporting Scheme has been collecting data on pharmacy compounding errors, including near-misses, since 2003.

Objectives The cumulative reports from January 2004 to December 2007, inclusive, were analysed.

Methods The different variables of product types, error types, staff making and detecting errors, stage errors detected, perceived contributory factors, and potential or actual outcomes were presented by cross-tabulation of data.

Results A total of 4691 reports were submitted against an estimated 958532 items made, returning $0.49 \%$ as the overall error rate. Most of the errors were detected before reaching patients, with only 24 detected during or after administration. The highest number of reports related to adult cytotoxic preparations $(40 \%)$ and the most frequently recorded error was a labelling error $(34.2 \%)$. Errors were mostly detected at first check in assembly area (46.6\%). Individual staff error contributed most (78.1\%) to overall errors, while errors with paediatric parenteral nutrition appeared to be blamed on low staff levels more than other products were. The majority of errors (68.6\%) had no potential patient outcomes attached, while it appeared that paediatric cytotoxic products and paediatric parenteral nutrition were associated with greater levels of perceived patient harm.

Conclusions The majority of reports were related to near-misses, and this study highlights scope for examining current arrangements for checking and releasing products, certainly for paediatric cytotoxic and paediatric parenteral nutrition preparations within aseptic units, but in the context of resource and capacity constraints.
\end{abstract}

\section{INTRODUCTION}

Errors associated with the prescribing, preparation and administration of injectable medicines in secondary care has attracted much attention with studies indicating that errors with injectables occur at a higher rate than with other forms of medicines. ${ }^{1-6}$ According to the UK's National Patient Safety Agency (NPSA) recommendations for making injectable medicines safer, some high-risk injectables namely all cytotoxic and total parenteral nutrition (TPN) products and all additions to TPN must be compounded in the pharmacy to minimise risks associated with their preparation. ${ }^{7}$ This particular policy is not new to the UK where pharmacy departments have been involved in the preparation and supply of intravenous injections since the Breckenridge Report. ${ }^{8}$ Nowadays, as well as cytotoxic products and TPNs, some hospital aseptic units offer a central intravenous additive service (CIVAS) for the preparation of antibiotic, analgesic and other injections and infusions. ${ }^{9}$

The aseptic preparation of medicines in the UK may be carried out in units holding a Manufacturers Specials Licence from the Medicines and Healthcare Products Regulatory Agency (MHRA) or in unlicensed units under Section 10 exemption from the licensing requirements of the Medicines Act provided a number of conditions are met, and there is an acceptable level of quality assurance (OA) together with regular external audit. ${ }^{10}$ The development and implementation of technical policy on pharmaceutical OA issues and the coordination of the monitoring of quality in relation to medicinal products prepared in and purchased by hospitals in the UK are carried out by the NHS Pharmaceutical Quality Assurance Committee (NHSPOAC) against accepted standards. ${ }^{10}$ No area of practice is without risk, and pharmacy aseptic services have not been without error. ${ }^{11}$ For example, there was a serious incident in the UK in 1994 where the administration of contaminated TPN resulted in the death of two infants, but in general there is very little in the academic literature about errors in pharmacy-controlled aseptic preparation units. The National Aseptic Error Reporting Scheme (NAERS) has been collecting data on pharmacy compounding errors via regional pharmacy $\mathrm{OA}$ specialists in the UK and returning quarterly summary reports since August 2003. ${ }^{12}$ The NPSA defines a patient safety incident as any unintended or unexpected incident which could have or did lead to harm for one or more patients receiving NHS care, with prevented patient safety incidents being defined as 'near misses. ${ }^{13}$ The NAERS database is unique because it collects data on all patient safety incidents including in-process errors that do not reach the patient (near-misses). ${ }^{12}$ In fact, the vast majority of the NAERS errors are near misses and have been detected before the product leaves the pharmacy, so they are classed as prevented patient safety incidents.

The point of preparing intravenous injections within hospital pharmacy units is to minimise risks associated with their preparation in clinical areas and improve the quality of the final product. ${ }^{14}$ While any health professional can potentially commit an error or violate a procedure at some point in their practice, the past decade has seen a shift in focus away from scrutinising the individual, 
Table 1 Numbers of errors recorded according to types of error involved for each category of product

\begin{tabular}{|c|c|c|c|c|c|c|c|c|c|c|c|}
\hline \multirow[b]{2}{*}{ Product type } & \multicolumn{11}{|l|}{ Error type } \\
\hline & Transcription & Calculation & Drug & Dose/strength & Diluent & Final vol. & Label & Expiry & Container & Other & Total \\
\hline Cytotoxic adult & $211(10.3 \%)$ & $70(3.4 \%)$ & $49(2.4 \%)$ & $94(4.6 \%)$ & $126(6.2 \%)$ & $110(5.4 \%)$ & $826(40.4 \%)$ & $188(9.2 \%)$ & $50(2.4 \%)$ & $323(15.8 \%)$ & 2047 \\
\hline Cytotoxic paediatric & $11(8.5 \%)$ & $4(3.1 \%)$ & $1(0.8 \%)$ & $10(7.8 \%)$ & $4(3.1 \%)$ & $3(2.3 \%)$ & $57(44.2 \%)$ & $13(10.1 \%)$ & $1(0.8 \%)$ & $25(19.4 \%)$ & 129 \\
\hline $\begin{array}{l}\text { Parenteral } \\
\text { nutrition—adult }\end{array}$ & $93(13.1 \%)$ & $63(8.9 \%)$ & $86(12.1 \%)$ & $59(8.3 \%)$ & $8(1.1 \%)$ & $23(3.2 \%)$ & $220(30.9 \%)$ & $11(1.5 \%)$ & $7(1 \%)$ & $141(19.8 \%)$ & 711 \\
\hline $\begin{array}{l}\text { Parenteral } \\
\text { nutrition-paediatric }\end{array}$ & 35 (19\%) & $18(9.8 \%)$ & $23(12.5 \%)$ & $12(6.5 \%)$ & $4(2.2 \%)$ & $17(9.2 \%)$ & $21(11.4 \%)$ & $7(3.8 \%)$ & $6(3.3 \%)$ & $41(22.3 \%)$ & 184 \\
\hline $\begin{array}{l}\text { Other intravenous } \\
\text { additive }\end{array}$ & $140(10.8 \%)$ & $90(6.9 \%)$ & $29(2.2 \%)$ & 57 (4.4\%) & $54(4.2 \%)$ & 141 (10.9\%) & $417(32.1 \%)$ & $102(7.9 \%)$ & $39(3 \%)$ & $229(17.6 \%)$ & 1298 \\
\hline $\begin{array}{l}\text { Other prefilled } \\
\text { syringes }\end{array}$ & $35(11.1 \%)$ & $10(3.2 \%)$ & $15(4.8 \%)$ & $12(3.8 \%)$ & $8(2.5 \%)$ & $15(4.8 \%)$ & $83(26.4 \%)$ & $25(8 \%)$ & $3(1 \%)$ & $108(34.4 \%)$ & 314 \\
\hline Other & $20(9.1 \%)$ & $11(5 \%)$ & $7(3.2 \%)$ & $11(5 \%)$ & $10(4.5 \%)$ & $10(4.5 \%)$ & $46(20.9 \%)$ & $17(7.7 \%)$ & $8(3.6 \%)$ & $80(36.4 \%)$ & 220 \\
\hline Data missing & $2(4.4 \%)$ & $4.0(8.9 \%)$ & 0 & $1(2.2 \%)$ & $1(2.2 \%)$ & $3(6.7 \%)$ & $20(44.4 \%)$ & $8(17.8 \%)$ & 0 & $6(13.3 \%)$ & 45 \\
\hline Total & 547 (11.1\%) & $270(5.5 \%)$ & $210(4.2 \%)$ & $256(5.2 \%)$ & 215 (4.3\%) & $322(6.5 \%)$ & $1690(34.2 \%)$ & $371(7.5 \%)$ & $114(2.3 \%)$ & $953(19.3 \%)$ & 4948 \\
\hline
\end{tabular}

towards rectifying the systems and general practices that lead to unsafe events. ${ }^{15}$ Understanding the context in which compounding errors occur thus becomes an important part of the OA process towards the enhancement of safety.

While recent UK patient safety initiatives are aimed at improving the safety of injectable medicines in clinical areas, ${ }^{7}$ the current study reports on safety within pharmacy production units. The cumulative error reports relating to the preparation of aseptic products in UK hospital pharmacies as collected by NAERS from January 2004 to December 2007, inclusive, were analysed. The present paper summarised the compounding errors reported to NAERS to include product categories, types of errors, the staff involved in making and detecting the errors, the stage at which errors were detected, perceived contributory factors, and potential or actual outcomes. Our aim was to investigate the NAERS reports in order to provide an understanding of the errors being made and reported to the database.

\section{METHODS}

The collection of data by NAERS has been described elsewhere ${ }^{12}$ and is detailed in Appendix 1 (web-only material) with the reporting categories detailed in Appendix 2 (web-only material). A total of 43 hospital pharmacies participate fully or partially in the Scheme. For the purpose of the current analysis, the cumulative data for the period January 2004 to December 2007 were collated onto one spreadsheet and exported to the software package SPSS (SPSS, Chicago, Illinois). The different variables were presented by cross-tabulation of the data. The study dealt with anonymised data and was approved by the Kingston University, Faculty of Science Research Ethics Committee.

\section{RESULTS}

There were a total of 4691 lines of data (reports) for the period January 2004 to December 2007, inclusive. An estimated 958532 items were made during the same period; thus, $0.49 \%$ of items made were associated with at least one error. Most of the reports related to the adult cytotoxic product (40\%), followed by other intravenous additives (27\%), adult parenteral nutrition $(15 \%)$, other prefilled syringes (7\%), paediatric parenteral nutrition (4\%) and paediatric cytotoxic preparations (2\%) with $5 \%$ recorded as other product and 1\% not recorded. Only 24 of the errors in the current study were detected during or after administration to the patient, so the majority of the reports related to near-misses.

\section{Types of error according to product type}

There was provision for more than one type of error to be recorded for any one product; consequently, a total of 4948 errors were recorded for the 4691 lines of data (see table 1). The most frequently recorded error was a labelling error (34.2\%) followed by transcription errors (11.1\%), incorrect expiry $(7.5 \%)$, final volume errors $(6.5 \%)$, calculation errors $(5.5 \%)$, incorrect dose/strength (5.2\%), incorrect diluent/infusion fluid (4.3\%), incorrect drug (4.2\%), and incorrect containers (2.3\%) with $19.3 \%$ of errors recorded as 'other.' While different types of error were recorded for all the product categories, certain error types were reported more with some preparations (see table 1).

\section{Personnel involved in detecting and making the errors}

There was provision, where appropriate, for the involvement of more than one person in any one error to be recorded; consequently, a total of 5527 people were reported to have contributed

Table 2 Numbers of personnel involved in detecting and making the reported errors

\begin{tabular}{|c|c|c|c|c|c|c|c|c|c|c|c|}
\hline \multirow[b]{2}{*}{ Error made by } & \multicolumn{11}{|c|}{ Error detected by } \\
\hline & Pharmacist & Technician & ATO & Student technician & Pre Reg & Nurse & Doctor & Patient & Other & Missing & Total \\
\hline Pharmacist & $305(36.3 \%)$ & $210(25.0 \%)$ & $62(7.4 \%)$ & $7(0.8 \%)$ & $1(0.1 \%)$ & $150(17.8 \%)$ & $11(1.3 \%)$ & $7(0.8 \%)$ & $38(4.5 \%)$ & $50(5.9 \%)$ & 841 \\
\hline АТО & $590(41.9 \%)$ & $626(44.4 \%)$ & $125(8.9 \%)$ & $6(0.4 \%)$ & $5(0.4 \%)$ & $33(2.3 \%)$ & $1(0.1 \%)$ & $1(0.1 \%)$ & $21(1.5 \%)$ & $1(0.1 \%)$ & 1409 \\
\hline $\begin{array}{l}\text { Student } \\
\text { technician }\end{array}$ & $82(49.4 \%)$ & $70(42.2 \%)$ & $9(5.4 \%)$ & $3(1.8 \%)$ & 0 & $2(1.2 \%)$ & 0 & 0 & 0 & 0 & 166 \\
\hline Pre Reg & $80(63.0 \%)$ & $40(31.5 \%)$ & $3(2.4 \%)$ & 0 & $2(1.6 \%)$ & $1(0.8 \%)$ & 0 & $1(0.8 \%)$ & 0 & 0 & 127 \\
\hline Doctor & $5(45.5 \%)$ & $5(45.5 \%)$ & 0 & 0 & 0 & $1(9.1 \%)$ & 0 & 0 & 0 & 0 & 11 \\
\hline Patient & 1 (50.0\%) & $1(50.0 \%)$ & 0 & 0 & 0 & 0 & 0 & 0 & 0 & 0 & 2 \\
\hline Other & $8(14.3 \%)$ & $31(55.4 \%)$ & $12(21.4 \%)$ & $1(1.8 \%)$ & $1(1.8 \%)$ & $1(1.8 \%)$ & 0 & 0 & 0 & $2(3.6 \%)$ & 56 \\
\hline Missing & $50(67.6 \%)$ & 9 (12.2\%) & $1(1.4 \%)$ & 0 & 0 & $4(5.4 \%)$ & 0 & 0 & $2(2.7 \%)$ & 8 (10.8\%) & 74 \\
\hline Total & 2502 (45.3\%) & 2148 (38.9\%) & 309 (5.6\%) & $29(0.5 \%)$ & $17(0.3 \%)$ & 304 (5.5\%) & $18(0.3 \%)$ & $18(0.3 \%)$ & $108(2.0 \%)$ & 74 (1.3\%) & 5527 \\
\hline
\end{tabular}


Table 3 Stage at which errors were detected for each product type

\begin{tabular}{|c|c|c|c|c|c|c|c|c|c|c|}
\hline \multirow[b]{2}{*}{ Product type } & \multicolumn{10}{|c|}{ Stage at which error detected } \\
\hline & $\begin{array}{l}\text { First check in } \\
\text { assembly area }\end{array}$ & $\begin{array}{l}\text { Operator check } \\
\text { in preparation } \\
\text { area }\end{array}$ & $\begin{array}{l}\text { During } \\
\text { labelling }\end{array}$ & $\begin{array}{l}\text { Final check } \\
\text { prior to } \\
\text { release }\end{array}$ & $\begin{array}{l}\text { At release } \\
\text { stage }\end{array}$ & $\begin{array}{l}\text { In clinical } \\
\text { area prior to } \\
\text { administration }\end{array}$ & $\begin{array}{l}\text { In clinical area } \\
\text { during or after } \\
\text { administration }\end{array}$ & Other & $\begin{array}{l}\text { Not } \\
\text { recorded }\end{array}$ & Total \\
\hline Cytotoxic adult & 1045 (55.9\%) & $109(5.8 \%)$ & $47(2.5 \%)$ & $451(24.1 \%)$ & $65(3.5 \%)$ & $108(5.8 \%)$ & $7(0.4 \%)$ & $31(1.7 \%)$ & $5(0.3 \%)$ & 1868 \\
\hline $\begin{array}{l}\text { Cytotoxic } \\
\text { paediatric }\end{array}$ & $27(24.3 \%)$ & $11(9.9 \%)$ & $5(4.5 \%)$ & $41(36.9 \%)$ & $6(5.4 \%)$ & $16(14.4 \%)$ & $1(0.9 \%)$ & $4(3.6 \%)$ & 0 & 111 \\
\hline $\begin{array}{l}\text { Parenteral } \\
\text { nutrition—adult }\end{array}$ & $383(56.2 \%)$ & $56(8.2 \%)$ & $30(4.4 \%)$ & $99(14.5 \%)$ & $43(6.3 \%)$ & $22(3.2 \%)$ & $4(0.6 \%)$ & $43(6.3 \%)$ & $1(0.1 \%)$ & 681 \\
\hline $\begin{array}{l}\text { Parenteral } \\
\text { nutrition- } \\
\text { paediatric }\end{array}$ & $74(41.3 \%)$ & $21(11.7 \%)$ & 0 & $47(26.3 \%)$ & $16(8.9 \%)$ & $7(3.9 \%)$ & $3(1.7 \%)$ & $11(6.1 \%)$ & 0 & 179 \\
\hline $\begin{array}{l}\text { Other intravenous } \\
\text { additive }\end{array}$ & $504(39.3 \%)$ & $179(14.0 \%)$ & $128(10.0 \%)$ & $262(20.5 \%)$ & $110(8.6 \%)$ & $35(2.7 \%)$ & $6(0.5 \%)$ & $56(4.4 \%)$ & $1(0.1 \%)$ & 1281 \\
\hline $\begin{array}{l}\text { Other prefilled } \\
\text { syringes }\end{array}$ & $60(19.4 \%)$ & $24(7.7 \%)$ & $4(1.3 \%)$ & $76(24.5 \%)$ & $78(25.2 \%)$ & $9(2.9 \%)$ & $1(0.3 \%)$ & $58(18.7 \%)$ & 0 & 310 \\
\hline Other & $68(31.3 \%)$ & $33(15.2 \%)$ & $7(3.2 \%)$ & $35(16.1 \%)$ & $40(18.4 \%)$ & $3(1.4 \%)$ & $2(0.9 \%)$ & $26(12 \%)$ & $3(1.4 \%)$ & 217 \\
\hline Not recorded & $24(54.5 \%)$ & $3(6.8 \%)$ & $3(6.8 \%)$ & $8(18.2 \%)$ & $2(4.5 \%)$ & $2(4.5 \%)$ & 0 & 0 & $2(4.5 \%)$ & 44 \\
\hline Total & $2185(46.6 \%)$ & $436(9.3 \%)$ & $224(4.8 \%)$ & $1019(21.7 \%)$ & $360(7.7 \%)$ & $202(4.3 \%)$ & $24(0.5 \%)$ & $229(4.9 \%)$ & $12(0.3 \%)$ & 4691 \\
\hline
\end{tabular}

to the 4691 error reports (see table 2). Technicians were the most likely personnel to be associated with making an error (51.2\%), followed by ATOs (25.5\%) and pharmacists (15.2\%). The involvement of other personnel stood at less than $7 \%$ in total. Pharmacists were most likely to detect errors (45.3\%) compared with technicians (38.9\%) and ATOs (5.6\%).

\section{Stages at which errors were detected for product type and error type}

The stages at which errors were detected for each product type were examined (see table 3 ). Figure 1 is a flow chart showing the

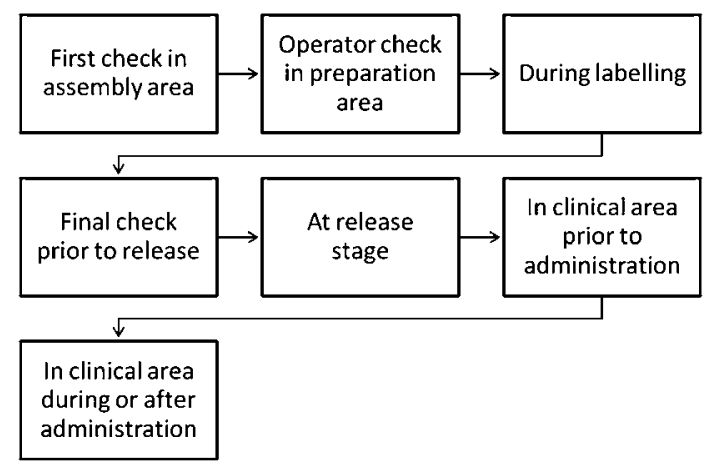

Figure 1 Flow chart of the drug use process from production to administration illustrating the seven stages for error detection. drug use process from production to administration and illustrates the opportunities for error detection as seven distinct stages. Errors were mostly detected at first check in assembly area $(46.6 \%)$, followed by final check prior to release $(21.7 \%)$, operator check in preparation area $(9.3 \%)$, at release stage $(7.7 \%)$, during labelling $(4.8 \%)$, in clinical area prior to administration $(4.3 \%)$, and in clinical area during or after administration $(0.5 \%)$ with $4.9 \%$ recorded as 'other' and $0.3 \%$ instances of non-recording. Errors with some products were detected to a larger extent than average at certain stages in the process. All types of error were detected at the various stages in the process (see table 4).

\section{Factors perceived to have contributed to errors}

The factors (5522) perceived to have contributed to errors with each product type were examined (see table 5 ). The highest rated factor $(78.1 \%)$ was that of individual staff error followed by distraction/interruption (4.3\%), inadequate training $(3.7 \%)$, workload above planned capacity (3.2\%), staffing level below establishment $(3.1 \%)$, inadequate computer system $(2 \%)$, process design (1.7\%), poor storage/distribution (0.8\%), facility/ equipment error $(0.8 \%)$, poor segregation $(0.6 \%)$ and poor quality of starting materials used $(0.4 \%)$ with $1.4 \%$ not recorded.

\section{Potential impact of error}

When potential outcomes of the errors as potential for impact on the patient were examined, it was found that the majority

Table 4 Stage at which errors were detected for each error type

\begin{tabular}{|c|c|c|c|c|c|c|c|c|c|c|}
\hline \multirow[b]{2}{*}{ Error type } & \multicolumn{10}{|c|}{ Stage at which error detected } \\
\hline & $\begin{array}{l}\text { First check in } \\
\text { assembly area }\end{array}$ & $\begin{array}{l}\text { Operator check } \\
\text { in preparation } \\
\text { area }\end{array}$ & $\begin{array}{l}\text { During } \\
\text { labelling }\end{array}$ & $\begin{array}{l}\text { Final check } \\
\text { prior to } \\
\text { release }\end{array}$ & $\begin{array}{l}\text { At release } \\
\text { stage }\end{array}$ & $\begin{array}{l}\text { In clinical } \\
\text { area prior to } \\
\text { administration }\end{array}$ & $\begin{array}{l}\text { In clinical area } \\
\text { during or after } \\
\text { administration }\end{array}$ & Other & Missing & Total \\
\hline Calculation & $166(61.5 \%)$ & $33(12.2 \%)$ & $10(3.7 \%)$ & $35(13.0 \%)$ & $10(3.7 \%)$ & $4(1.5 \%)$ & $1(0.4 \%)$ & $11(4.1 \%)$ & 0 & 270 \\
\hline Drug & $140(66.7 \%)$ & $29(13.8 \%)$ & $2(1.0 \%)$ & 27 (12.9\%) & $6(2.9 \%)$ & $1(0.5 \%)$ & $1(0.5 \%)$ & $4(1.9 \%)$ & 0 & 210 \\
\hline Dose/strength & $114(44.5 \%)$ & $32(12.5 \%)$ & $8(3.1 \%)$ & $52(20.3 \%)$ & $24(9.4 \%)$ & $14(5.5 \%)$ & $3(1.2 \%)$ & $9(3.5 \%)$ & 0 & 256 \\
\hline Label & $920(54.4 \%)$ & $34(2 \%)$ & $59(3.5 \%)$ & $435(25.7 \%)$ & $100(5.9 \%)$ & $106(6.3 \%)$ & $3(0.2 \%)$ & $31(1.8 \%)$ & $2(0.1 \%)$ & 1690 \\
\hline Expiry & $201(54.2 \%)$ & $3(0.8 \%)$ & $16(4.3 \%)$ & $86(23.2 \%)$ & $17(4.6 \%)$ & $29(7.8 \%)$ & $4(1.1 \%)$ & $15(4.0 \%)$ & 0 & 371 \\
\hline Container & $49(43 \%)$ & $33(28.9 \%)$ & $1(0.9 \%)$ & 17 (14.9\%) & $4(3.5 \%)$ & $4(3.5 \%)$ & 0 & $5(4.4 \%)$ & $1(0.9 \%)$ & 114 \\
\hline Other & $246(25.8 \%)$ & $166(17.4 \%)$ & $39(4.1 \%)$ & $187(19.6 \%)$ & $143(15.0 \%)$ & $29(3.0 \%)$ & $7(0.7 \%)$ & $129(13.5 \%)$ & $7(0.7 \%)$ & 953 \\
\hline Total & $2325(47 \%)$ & 455 (9.2\%) & $235(4.7 \%)$ & $1067(21.6 \%)$ & $369(7.5 \%)$ & $217(4.4 \%)$ & $24(0.5 \%)$ & $243(4.9 \%)$ & $13(0.3 \%)$ & 4948 \\
\hline
\end{tabular}




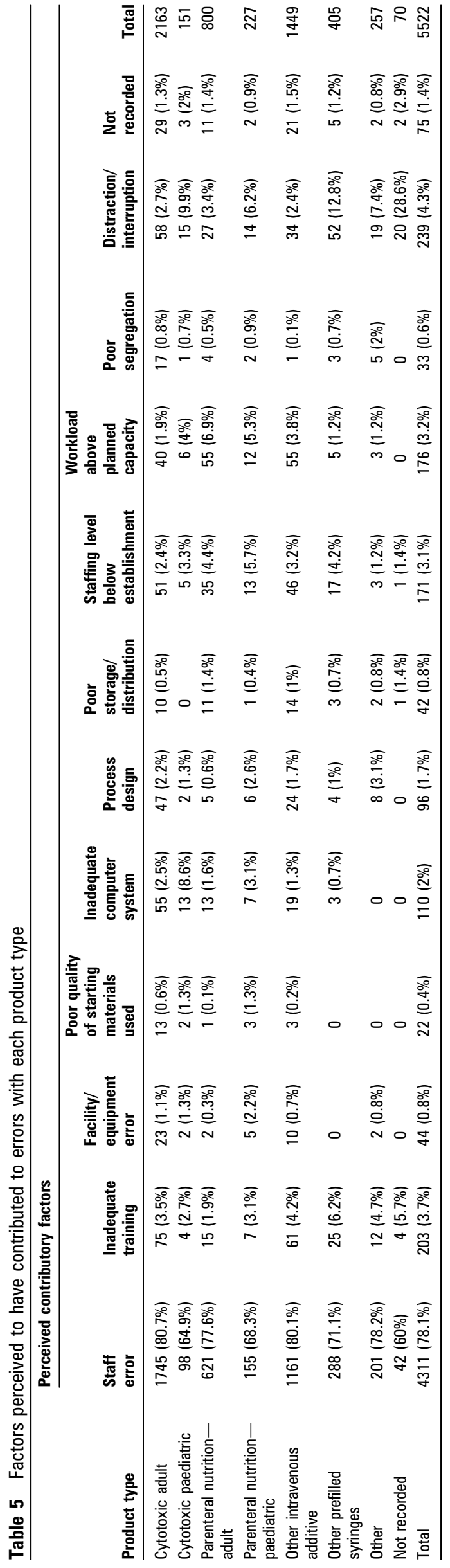

(68.6\%) were reported to have no potential outcomes associated with them, $18.4 \%$ a minor outcome, $3.9 \%$ a moderate outcome, $2.6 \%$ major and $0.1 \%$ (four reports) a potentially catastrophic outcome-the latter were all near-misses identified before reaching clinical areas (see table 6). The potential outcome was not recorded in $6.4 \%$ of the reports.

\section{DISCUSSION}

This is the first study to report on the cumulative errors detected and reported by pharmacy compounding units in the UK to include the categories of product involved, types of error, the stage at which errors were detected, perceived contributory factors, and potential or actual outcomes. Only 24 of the errors in the current study were detected during or after administration to the patient, so the majority of the reports relate to near-misses. The estimated overall compounding error rate of $0.49 \%$ compared well with $0.45 \%$ reported in a study using similar methodology ${ }^{16}$ but not with an observational study that found a mean error rate of $9 \%{ }^{17}$ for intravenous compounding in the pharmacy. Measuring error rates is notoriously challenging, and incident reporting can underestimate the true rate of error, ${ }^{18}$ which could explain the difference noted above. Nonetheless, these figures are in sharp contrast to an often-quoted observational study that found that $49 \%$ of intravenous doses prepared in clinical areas contained at least one mistake ${ }^{1}$ and another that found that $43 \%$, $99 \%$ and $20 \%$ of doses prepared in UK, German and French hospital wards, respectively, contained a labelling error. ${ }^{3}$

Our primary aim was to develop a better understanding of factors associated with the errors that had been detected and reported to NAERS. A total of $40 \%$ of errors related to adult cytotoxic preparations, which could simply relate to high quantities of these products being made by pharmacy compounding units. However, this type of product involves largely the preparation of patient-specific doses according to body surface area and as such the handling of variable data, which could present more scope for errors and partly explain the pattern of error types found. The preparation of individualised chemotherapy doses involves several steps, and that could also add to the problems observed. The findings might also lend credence to the argument for the dose-banding of adult cytotoxic preparations where standard doses can be provided using a selection of prefilled infusions or syringes, ${ }^{19}$ further streamlining the production process. The findings certainly highlight a need for uniform and robust final checks to ensure that when they occur, errors with cytotoxic product do not leave compounding units.

By examining the cross-tabulated data, it appeared that staffing level being below establishment and workload above planned capacity were thought to have impacted on errors with parenteral nutrition products more than with other products. The preparation of parenteral nutrition is complex, and even where standardised multicompartment bags are used, compounding will still involve the addition of a number of extra components such as vitamins, trace elements and electrolytes according to patient needs. Also, it is the authors' experience that many units prepare parenteral nutrition in the last work session of the day, which could contribute to the observed errors. Our findings are in the context of an underlying resource and capacity issue, where there are known recruitment and capacity problems within pharmacy technical services in the UK. ${ }^{20-26}$ This presents a particular challenge because while studies indicate that a large percentage of high-risk compounding still takes place in clinical areas, ${ }^{27}$ these will need to be transferred to specialised pharmacy units. 
Table 6 Reported potential outcomes according to product type

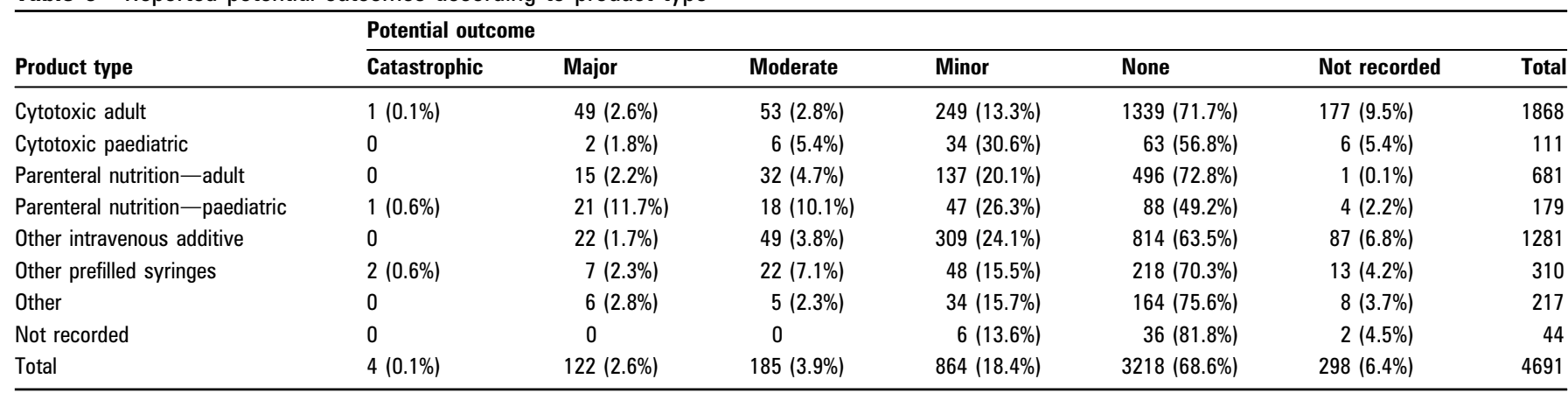

By examining the cross-tabulated data it also appeared that errors with paediatric parenteral nutrition were associated with minor, moderate and major outcomes more than other products were. This perhaps reflects the complexity of the process of compounding paediatric parenteral nutrition and the typical number of ingredients used. ${ }^{28}$ It also appeared that errors with paediatric parenteral nutrition were detected in clinical areas during or after administration more than other products were, which highlights again the need for robust final check and release procedures to stop these errors from leaving the production area. The same applies to errors with paediatric cytotoxic products that appeared to be detected at later stages in the process, such as at final check prior to release and in clinical areas prior to administration more than other products were. The checks are especially important in the context of staff shortages.

Errors with other prefilled syringes appeared to be judged as having moderate potential outcome for the patient more than other products were and were also mostly detected at release stage $(25.2 \%)$. This is perhaps to be expected because the supply of prefilled syringes is more akin to a dispensing operation where the final check is essentially the main part of the checking process. Errors with other prefilled syringes appeared to be attributed to inadequate training, and distractions and interruptions more than other products were, and this is worth considering for those who manage pharmacy aseptic units. The majority of all errors were reported to have been made by technicians most likely because technicians are involved in preparing products more than any other staff. The majority of all errors were reported to have been detected by pharmacists, and again this reflects the standard pattern of work in pharmacy departments, where technicians have overall responsibility for the preparation of work and pharmacists for the final check.

\section{Strengths and weaknesses of the study}

Since the majority of the reports related to near-misses, the data should be seen in the context of errors that were picked up and reported to NAERS rather than errors that had reached the patient. The NAERS reporting system is well publicised within the participating hospital production units and is now an established Scheme in its fifth year of operation; nonetheless, the main weakness of this study is the fact that it relies on detection and self-reporting of errors by staff working within these units. In addition, although the cross-tabulation of data implies certain patterns of association, where high numbers were reported in any one category, this may simply be a virtue of low reporting with the other categories of data. The authors acknowledge there would be variability between staff, even in the same unit, in the number of reports detected and submitted to the Scheme.
These factors perhaps explain the difference between the rates of error reported in this study and those found in an observational study. There could also be variability in the qualitative judgements made-for example, when assessing criteria such as the potential impact of a near miss. The categories of data analysed relate to an initial reporting template which was piloted and distributed for use at the outset of the Scheme. The Scheme may need to be updated to take account of areas where the category 'other' was overused. Also, because the majority of the reports submitted to NAERS relate to near-misses, the data could be a reflection of the existence of effective error detection and reporting processes, rather than highlighting real problem areas that in fact escape detection and reporting. Effective checking and screening procedures allied to a reporting system can potentially maximise patient safety. Importantly, because the Scheme does not collect information on items made per product type, the frequency of errors found within each product category cannot be contextualised any further. Nonetheless, as it stands, this study makes a valuable contribution to the OA of pharmacy production units by highlighting possible relationship between the various categories of errors, as summarised below.

\section{Implications}

Our study shows that where pharmacy compounding errors are detected and reported, these relate mainly to adult cytotoxic preparations, which may relate to high volumes being produced or may be the result of the variety of processes involved in the compounding these products. The majority of the errors were near-misses, but errors with paediatric parenteral nutrition preparations, although small in number, appeared to be detected and reported as accidents that had reached the patient more than other products were. Errors with all paediatric preparations also appeared to be associated with the greater levels of perceived patient harm. The findings could be seen as a startingpoint from which better error detection and reporting systems can be developed and further monitored in due course. The areas of weakness identified by this study can be used to introduce additional and perhaps more robust checks within individual aseptic units and contribute more globally to the programme of OA conducted by NHSPOAC, but any changes will need to take place with due consideration of existing resource and capacity issues within NHS aseptic units.

\section{CONCLUSIONS}

While the majority of the reports related to near-misses, our study highlights the possibility of certain relationships that can be used to improve the reporting, analysis and management of pharmacy compounding errors in the future. Certainly, there is scope for examining current arrangements for the checking and 
release of paediatric products, which appeared to be detected in clinical wards areas more than other products were and also appeared to be linked to a greater potential for patient harm, but any changes would need to take place in the context of resource and capacity constraints.

Acknowledgements The authors would like to thank all NHS staff involved in collating and submitting the error reports to NAERS. In addition, the authors would like to thank the University of Reading Statistical Advisory Service for the kind provision of statistical guidance.

Competing interests The corresponding author is the Chairman of the NHS Pharmaceutical Quality Assurance Committee (NHSPQAC). The authors' work was independent of NHSPQAC.

Ethics approval Ethics approval was provided by the Kingston University, Faculty of Science Research Ethics Committee.

Provenance and peer review Not commissioned; externally peer reviewed.

\section{REFERENCES}

1. Taxis $\mathbf{K}$, Barber N. Ethnographic study of incidence and severity of intravenous medicine errors. BMJ 2003;326:684-7.

2. Taxis $\mathbf{K}$, Barber N. Causes of intravenous medication errors: an ethnographic study. Qual Saf Health Care 2003;12:343-7.

3. Cousins DH, Sabatier B, Begue D, et al. Medication errors in intravenous medicine preparation and administration: a multicentre audit in the UK, Germany and France. Qual Saf Health Care 2005;14:190-5.

4. Wirtz V, Taxis K, Barber ND. An observational study of intravenous medication errors in the United Kingdom and in Germany. Pharm World Sci 2003;25:104-11.

5. O'Hare MCB, Gallagher T, Shields MD. Errors in the administration of intravenous drugs. BMJ 1995:10:1536-7.

6. Hartley GM, Dhillon S. An observational study of the prescribing and administration of intravenous drugs in a general hospital. Int J Pharm Pract 1998:6:38-45.

7. National Patient Safety Agency. Patient safety alert number 20, promoting safer use of injectable medicines. National Patient Safety Agency: 2007. http://www.nrls. npsa.nhs.uk/resources/?entryid45 $=59812$.

8. Breckenridge A. Report of the working party on the addition of drugs to intravenous infusion fluids [HC(76)9] [Breckenridge report]. London: Department of Health and Social Security, 1976
9. Allwood MC. Practical guides. I: central intravenous additive services. J Clin Pharm Ther 1994; 19:137-45

10. Beaney AM. Quality assurance of aseptic preparation services. 4th edn. London: Pharmaceutical Press, 2005

11. Gandy RJ, Beaumont IM, Lee G, et al. Risk management and the aseptic preparation of medicines. European Hospital Pharmacy 1998;4,114-19.

12. Bateman R. Determining the rates and types of errors in pharmacy-managed aseptic preparation units. Hosp Pharm 2003;10:496-8.

13. National Patient Safety Agency. What is a patient safety incident. http://www. npsa.nhs.uk/nrls/reporting/what-is-a-patient-safety-incident/ laccessed 12 December 2009).

14. Hospital Pharmacists Group. Aseptic preparation: pharmacy's responsibility in managing risk. Pharm J 2002;268:193.

15. Stump LS. Re-engineering the medication error-reporting process: removing the blame and improving the system. Am J Health Syst Pharm 2000:57:S10-17.

16. Limat S, Drouhin JP, Demesmay K, et al. Incidence and risk factors of preparation errors in a centralized cytotoxic preparation unit. Pharm World Sci 2001:23:102-6.

17. Flynn EA, Pearson RE, Barker KN. Observational study of accuracy in compounding i.v. admixtures at five hospitals. Am J Health Syst Pharm 1997;54:904-12.

18. Brown C, Hofer $T$, Johal A, et al. An epistemology of patient safety research: a framework for study design and interpretation. Part 3. End points and measurement. Qual Saf Health Care 2008;17:170-7.

19. Plumridge RJ, Sewell GJ. Dose-banding of cytotoxic drugs: a new concept in cancer chemotherapy. Am J Health Syst Pharm 2001;58:1760-4

20. Department of health. Modernising the NHS hospital medicines manufacturing service, 2003. http://www.dh.gov.uk/en/Publicationsandstatistics/Publications/ PublicationsPolicyAndGuidance/DH_4003015. (accessed 28 May 2009).

21. Gandy RJ, Beaumont IM. Evaluating the impact of major investment in aseptic preparation on capacity and collaboration. Hosp Pharm 2006;13:221-5.

22. Gandy RJ, Beckford JLW, Booth MD. Secondary care coalface: the challenge of capacity management in aseptic preparation. Pharmacy Management 2006;22

23. Gandy RJ, Beaumont IM. Analysing aseptic preparation-workload measurement and capacity planning. Hosp Pharm 2003;10:328-37.

24. Gandy RJ, Beaumont IM. Analysing aseptic preparation-survey design and data assessment. Hosp Pharm 2003;10:338-47.

25. Dixon R, Forsey P, Morrison L. NHS technical specialists - strengthening the caree path. Hosp Pharm 2007;14:337.

26. NHS Pharmacy Education and Development Committee. National hospital pharmacy staffing survey 2006. http://www.nhspedc.nhs.uk/pdf/Survey2006.pdf.

27. Hardy L, Mellor L. Risk assessment of parenteral product preparation across secondary care acute trusts in the north of England. Hosp Pharm 2007;14:58-64.

28. Sobotka L, ed. Basics in clinical nutrition. 3rd edn. Prague: Galen, 2004. 